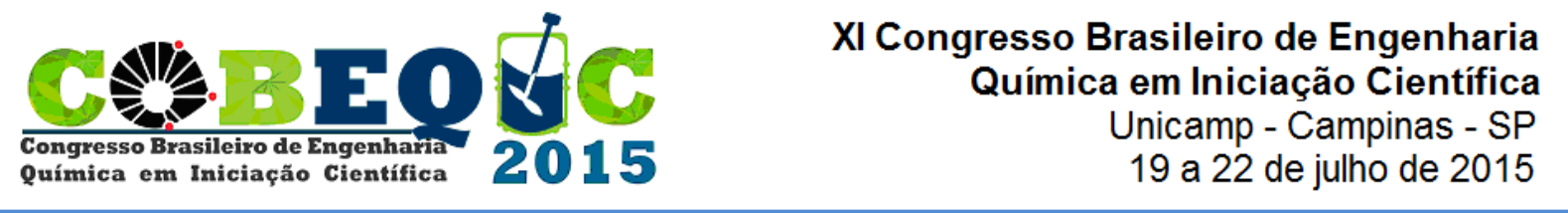

\title{
BENEFICIAMENTO DE PIRITA PROVENIENTE DA MINERAÇÃO DE CARVÃO
}

\author{
C. M. de OLIVEIRA ${ }^{1}$, C. M. MACHADO ${ }^{2}$ e M. PETERSON ${ }^{1,2}$ \\ ${ }^{1}$ Universidade do Extremo Sul Catarinense, Laboratório de Reatores e Processos Industriais \\ ${ }^{2}$ Universidade do Extremo Sul Catarinense, Departamento de Engenharia Química \\ E-mail para contato: machadodeoliveirac@gmail.com
}

\begin{abstract}
RESUMO - A pirita é um mineral de ampla ocorrência na natureza e encarada como rejeito quando proveniente da extração de carvão. Elevar seu grau de pureza fortalece a possibilidade de transformá-la em um subproduto de maior valor agregado. Neste sentido, sugere-se uma rota de beneficiamento do rejeito piritoso do sul de Santa Catarina (Brasil), baseada em separação densitária em bromofórmio e lixiviações sucessivas em água e solvente orgânico. Aplicaram-se metodologias estatísticas para definição dos parâmetros de lixiviação e a eficiência do processo foi avaliada e comprovada por determinação de enxofre total, difratometria de raios-X e espectrometria de infravermelho por transformada de Fourier.
\end{abstract}

\section{INTRODUÇÃO}

A pirita $\left(\mathrm{FeS}_{2}\right)$ é comum na crosta terrestre (Chandra e Gerson, 2010), correspondendo a maior parte dos resíduos sólidos gerados pela mineração do carvão (Nascimento et al., 2002). Embora considerada resíduo sólido, pode ser precursora de produtos como: enxofre, ácido sulfúrico, hematita, dióxido de enxofre, fertilizantes, sulfatos ferrosos (Peterson, 2008).

Oliveira et al. (2014) apresentaram estudos preliminares sobre beneficiamento de pirita proveniente da mineração de carvão sul catarinense. Os resultados tratam de uma rota baseada na dupla lixiviação do material "in natura" em água e posterior lixiviação em solução saturada de diclorometano. Os métodos adotados contribuíram para a redução do teor de matéria orgânica e sulfatos de ferro presentes no rejeito. Espectros de FTIR comprovaram que a fração caulinítica contida na pirita "in natura" não sofreu alterações com o processo.

Assim, pretende-se com este trabalho otimizar a rota de beneficiamento sugerida por Oliveira et al. (2014). Procedimentos estatísticos serão aplicados na determinação dos parâmetros de lixiviação e um método para remoção da fração argilosa será proposto.

\section{MATERIAIS E MÉTODOS}

A pirita estudada, coletada no município de Treviso (Brasil/SC), foi britada em britador mandíbula, moída em moinho de discos e, sequencialmente, moinho excêntrico com bolas de alta alumina. Para submissão aos processos listados, seu tamanho de partícula final médio foi de $250 \mu \mathrm{m}$. 
Lixiviação em água: Para redução do teor de sulfatos e demais solúveis, imergiu-se a pirita em água destilada, $50 \mathrm{~mL}$ de água por $1 \mathrm{~g}$ de material, e o sistema permaneceu sob agitação magnética (agitador Fisatom, modelo 752A). Na sequência, realizou-se filtração a vácuo (bomba a vácuo Prismatec, modelo 131) retendo a pirita no papel filtro. O material foi seco em estufa a vácuo Marconi, modelo MA 030/12 a $40{ }^{\circ} \mathrm{C}$. Parâmetros como temperatura da água, tempo de agitação e reprodução do processo foram definidos segundo metodologia estatística de um planejamento fatorial $2^{\mathrm{k}}$ com três fatores, apresentado na Tabela 1.

Lixiviação em solvente orgânico: Objetivando a redução do teor de orgânicos, realizouse um procedimento similar ao descrito para a lixiviação em água, substituindo apenas o solvente. O planejamento fatorial $2^{\mathrm{k}}$ com dois fatores encontra-se na Tabela 2. Os experimentos ocorreram à temperatura ambiente e para dois diferentes solventes: i. Solução $50 \%$ em volume de acetona (Lafan, 99,5\% P.A.); ii. Solução 0,23 M de diclorometano (Vetec, 99,5\% P.A.). Para cada $1 \mathrm{~g}$ de material a ser lixiviado, empregaram-se $50 \mathrm{~mL}$ de solução.

Tabela 1 - Planejamento fatorial $2^{\mathrm{k}}$ para análise dos parâmetros de lixiviação em água

\begin{tabular}{ccccccc}
\cline { 4 - 7 } Experimento & & & \multicolumn{3}{c}{ Fatores } \\
\hline Níveis & & $\begin{array}{c}\text { Temperatura } \\
\left({ }^{\circ} \mathrm{C}\right)\end{array}$ & $\begin{array}{c}\text { Tempo } \\
(\min )\end{array}$ & Reprodução \\
\hline 1a & -1 & -1 & -1 & 50 & 20 & 1 \\
$3 \mathrm{a}$ & +1 & -1 & -1 & 90 & 20 & 1 \\
$4 \mathrm{a}$ & -1 & +1 & -1 & 50 & 60 & 1 \\
$5 \mathrm{a}$ & +1 & +1 & -1 & 90 & 60 & 1 \\
$6 \mathrm{a}$ & -1 & -1 & +1 & 50 & 20 & 3 \\
$7 \mathrm{a}$ & +1 & -1 & +1 & 90 & 20 & 3 \\
$8 \mathrm{a}$ & -1 & +1 & +1 & 50 & 60 & 3 \\
$9 \mathrm{a}$ & +1 & +1 & +1 & 90 & 60 & 2 \\
$10 \mathrm{a}$ & 0 & 0 & 0 & 70 & 40 & 2 \\
$11 \mathrm{a}$ & 0 & 0 & 0 & 70 & 40 & 2 \\
\hline
\end{tabular}

Tabela 2 - Planejamento fatorial $2^{\mathrm{k}}$ para análise dos parâmetros de lixiviação em solvente orgânico

\begin{tabular}{|c|c|c|c|c|}
\hline \multirow[b]{2}{*}{ Experimento } & & & \multicolumn{2}{|c|}{ Fatores } \\
\hline & \multicolumn{2}{|c|}{ Níveis } & $\begin{array}{c}\text { Tempo } \\
\text { (min) }\end{array}$ & Reprodução \\
\hline $1 \mathrm{~b}$ & -1 & -1 & 20 & 1 \\
\hline $2 b$ & +1 & -1 & 60 & 1 \\
\hline $3 b$ & -1 & +1 & 20 & 3 \\
\hline $4 b$ & +1 & +1 & 60 & 3 \\
\hline $5 b$ & 0 & 0 & 40 & 2 \\
\hline $6 b$ & 0 & 0 & 40 & 2 \\
\hline $7 b$ & 0 & 0 & 40 & 2 \\
\hline
\end{tabular}


Adotou-se como variável resposta aos planejamentos o teor de enxofre, estimado com um equipamento LECO SC632.

A pirita utilizada nos experimentos das Tabelas 1 e 2 estava em seu estado "in natura". Após análise estatística dos dados e definição dos parâmetros dos processos de lixiviação, o rejeito piritoso foi submetido à separação densitária em bromofórmio puríssimo (P.A. 97\%) marca Vetec, densidade de 2,85-2,90 g/mL ( $4 \mathrm{~mL}$ de reagente por $1 \mathrm{~g}$ de material) e, sequencialmente, à lixiviação em água e em solvente orgânico. Ressalta-se que após a separação em bromofórmio, a pirita sedimentada foi lavada com álcool etílico.

A verificação das fases cristalinas presentes na pirita antes e após o processo de purificação se deu através da técnica de difração de raios-X (DRX). Os ensaios foram realizados em um difratômetro de raios-X (marca Shimadzu, modelo XRD-6000), goniômetro theta theta, radiação k- $\alpha$ com tubo de cobre de comprimento de onda $(\lambda)$ de $1,5406 \AA$. O passo realizado nas análises foi de $2 \%$ min. $\mathrm{O}$ range de medida foi de $\left(10\right.$ a $\left.80^{\circ}\right)$, com $30 \mathrm{kV}$ de voltagem e $30 \mathrm{~mA}$ de corrente elétrica.

Para o ensaio de espectrometria de infravermelho (FTIR), prepararam-se amostras por prensagem no formato de pastilha com uma proporção (aproximada) de 95\% de brometo de potássio $(\mathrm{KBr})$ e $5 \%$ de material a ser analisado. O equipamento utilizado foi um espectrofotômetro de FTIR (marca Shimadzu, modelo IR Prestige-21). A análise foi realizada por transmitância, com uma velocidade de $0,2 \mathrm{~cm} / \mathrm{s}$ e uma resolução de $4 \mathrm{~cm}^{-1}$ com um intervalo de 400 a $4000 \mathrm{~cm}^{-1}$.

\section{RESULTADOS E DISCUSSÃO}

As Tabelas 3 e 4 trazem os valores de teor de enxofre para as amostras dos planejamentos apresentados anteriormente.

Tabela 3 - Teor de enxofre para as amostras lixiviadas em água

\begin{tabular}{cccccc}
\hline \multirow{2}{*}{ Experimento } & \multicolumn{3}{c}{ Teor de enxofre (\%) } & \multirow{2}{*}{ Média } & \multirow{2}{*}{ Desvio Padrão } \\
\cline { 2 - 4 } & Réplica 1 & Réplica 2 & Réplica 3 & & \\
\hline 1a & 52,5 & 42,6 & 43,3 & 46,1 & 5,52 \\
2a & 42,0 & 43,3 & 42,2 & 42,5 & 0,70 \\
3a & 43,1 & 43,7 & 42,3 & 43,0 & 0,70 \\
4a & 43,2 & 43,5 & 43,4 & 43,4 & 0,15 \\
$5 \mathrm{a}$ & 44,0 & 42,8 & 43,2 & 43,3 & 0,61 \\
$6 \mathrm{a}$ & 43,7 & 43,8 & 44,6 & 44,0 & 0,49 \\
$7 \mathrm{a}$ & 45,4 & 45,4 & 44,1 & 45,0 & 0,75 \\
$8 \mathrm{a}$ & 43,9 & 43,4 & 44,4 & 43,9 & 0,50 \\
9a & 45,4 & 44,6 & 45,1 & 45,0 & 0,40 \\
$10 \mathrm{a}$ & 44,3 & 45,9 & 44,6 & 44,9 & 0,85 \\
$11 \mathrm{a}$ & 47,4 & 44,6 & 46,1 & 46,0 & 1,40 \\
\hline
\end{tabular}

O rejeito piritoso continha $38,8 \%$ de $\mathrm{S}$; uma pirita pura é composta por aproximadamente $53,5 \%$ deste elemento. Logo, através dos dados da Tabela 4 , verifica-se que 
maiores teores de enxofre (maior eficiência de purificação) foram alcançados com a solução de acetona. Por essa razão, esse solvente foi o preferido para a remoção da matéria orgânica presente na pirita.

Tabela 4 - Teor de enxofre para as amostras lixiviadas em solvente orgânico

\begin{tabular}{|c|c|c|c|c|c|c|}
\hline & \multirow{2}{*}{ Experimento } & \multicolumn{3}{|c|}{ Teor de enxofre $(\%)$} & \multirow{2}{*}{ Média } & \multirow{2}{*}{ Desvio padrão } \\
\hline & & Réplica 1 & Réplica 2 & Réplica 3 & & \\
\hline \multirow{7}{*}{ Acetona } & $1 \mathrm{~b}$ & 48,1 & 43,4 & 45,8 & 45,8 & 2,35 \\
\hline & $2 b$ & 45,9 & 46,2 & 47,6 & 46,6 & 0,91 \\
\hline & $3 b$ & 50,8 & 48,8 & 48,8 & 49,5 & 1,15 \\
\hline & $4 b$ & 50,8 & 50,2 & 50,4 & 50,5 & 0,31 \\
\hline & $5 b$ & 50,7 & 48,9 & 50,5 & 50,0 & 0,99 \\
\hline & $6 b$ & 50,1 & 50,0 & 49,2 & 49,8 & 0,49 \\
\hline & $7 b$ & 50,0 & 50,1 & 48,8 & 49,6 & 0,72 \\
\hline \multirow{7}{*}{ Diclorometano } & $1 b$ & 45,8 & 46,4 & 46,8 & 46,3 & 0,50 \\
\hline & $2 b$ & 45,4 & 46,1 & 45,3 & 45,6 & 0,44 \\
\hline & $3 b$ & 47,7 & 47,7 & 47,5 & 47,6 & 0,12 \\
\hline & $4 b$ & 45,8 & 47,7 & 46,4 & 46,6 & 0,97 \\
\hline & $5 b$ & 47,2 & 45,5 & 47,7 & 46,8 & 1,15 \\
\hline & $6 b$ & 47,0 & 45,7 & 47,4 & 46,7 & 0,89 \\
\hline & $7 b$ & 45,5 & 46,0 & 48,7 & 46,7 & 1,72 \\
\hline
\end{tabular}

O tratamento estatístico dos dados (Tabelas 5 e 6 ) mostrou que, com $99 \%$ de confiança e para o intervalo testado, nenhum dos fatores foi significativo para o teor de enxofre das amostras lixiviadas em água. Já para o tratamento em acetona, o fator reprodução foi significativo e apresentou efeito positivo: quanto maior o número de reproduções, maior o teor de enxofre.

Tabela 5 - Análise de Variância (ANOVA) aplicada aos valores de teor de enxofre das amostras lixiviadas em água

\begin{tabular}{cccccc}
\hline & Desvio padrão & Df & MS & Teste F & Teste P \\
\hline (1) Temperatura $\left({ }^{\circ} \mathrm{C}\right)$ & 5,0417 & 1 & 5,04167 & 1,446571 & 0,240347 \\
(2) Tempo (min) & 0,2017 & 1 & 0,20167 & 0,057863 & 0,811868 \\
(3) Reprodução & 0,5400 & 1 & 0,54000 & 0,154938 & 0,697197 \\
1 por 2 & 1,8150 & 1 & 1,81500 & 0,520765 & 0,477211 \\
1 por 3 & 3,2267 & 1 & 3,22667 & 0,925805 & 0,345170 \\
2 por 3 & 5,2267 & 1 & 5,22667 & 1,499651 & 0,232139 \\
$1 * 2 * 3$ & 12,3267 & 1 & 12,32667 & 3,536805 & 0,071720 \\
Erro & 87,1314 & 25 & 3,48525 & & \\
Desvio padrão total & 115,5097 & 32 & & &
\end{tabular}


Tabela 6 - Análise de Variância (ANOVA) aplicada aos valores de teor de enxofre das amostras lixiviadas em solução de acetona e efeitos estimados dos fatores

\begin{tabular}{cccccccccc}
\hline & Desvio padrão & Df & MS & Teste F & Teste P & Efeito & $\begin{array}{c}-99 \% \\
\text { Limite de } \\
\text { confiança }\end{array}$ & $\begin{array}{c}+99 \% \\
\text { Limite de } \\
\text { Confiança }\end{array}$ \\
\hline (1) Tempo (min) & 2,43000 & 1 & 2,43000 & 1,18280 & 0,291967 & 0,90000 & $-1,49839$ & 3,29839 \\
(2) Reprodução & 43,32000 & 1 & 43,32000 & 21,08590 & 0,000259 & 3,80000 & 1,40161 & 6,19839 \\
1 por 2 & 0,03000 & 1 & 0,03000 & 0,01460 & 0,905234 & 0,10000 & $-2,29839$ & 2,49839 \\
$\quad$ Erro & 34,92571 & 17 & 2,05445 & & & & & \\
Desvio padrão total & 80,70571 & 20 & & & & & & \\
\hline$\alpha=0,01 ; \mathrm{R}^{2}=0,56725$ & & & & & & & & &
\end{tabular}

Elencou-se como rota de beneficiamento, executada após separação densitária: i. Duas lixiviações consecutivas em água a $70{ }^{\circ} \mathrm{C}$ e por $40 \mathrm{~min}$; trabalhou-se com o ponto central do planejamento porque embora nenhum fator tenha se mostrado significativo, o baixo valor de $\mathrm{R}^{2}(0,24568)$ demostra que o modelo estatístico não foi o mais adequado na avaliação da influência dos parâmetros de lixiviação sobre a eficiência de purificação do rejeito; ii. Três lixiviações em solução de acetona por 20 minutos (fator reprodução foi significativo).

A Figura 1 traz os resultados de DRX. A intensidade dos picos correspondentes à pirita aumentou após o beneficiamento, indicando possível acréscimo na concentração do mineral.

Figura 1 - Difratogramas de raios-X das piritas. P: pirita e I: indefinido

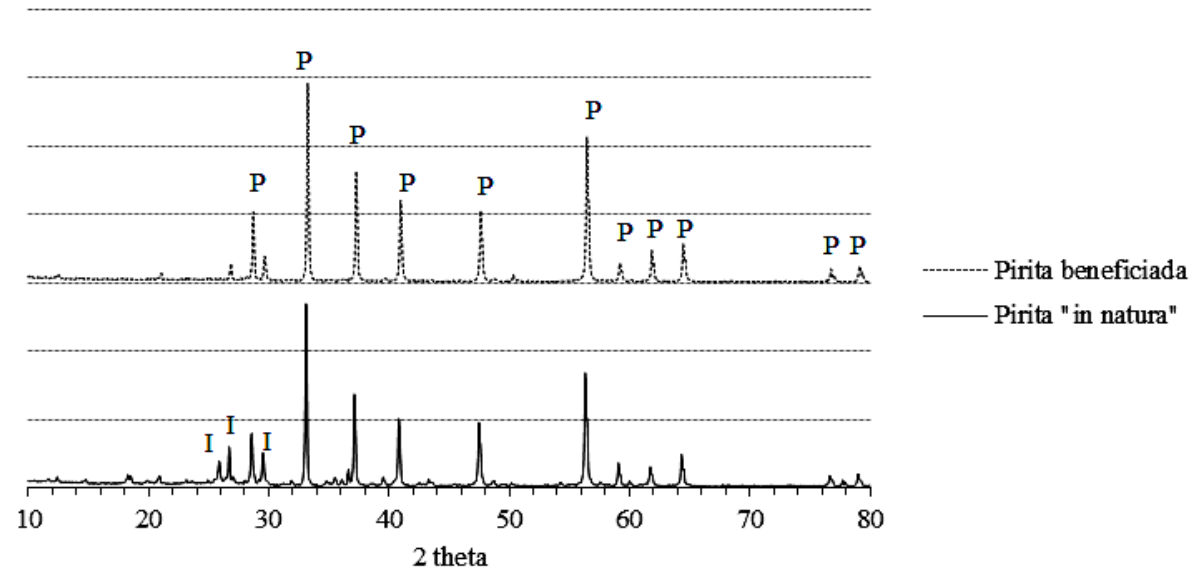

De acordo com o trabalho de Oliveira et al. (2014), os espectros de FTIR da Figura 2 apontam a presença de sulfatos de ferro na pirita "in natura", bandas próximas e entre os intervalos de 900 a $1200 \mathrm{~cm}^{-1}$ e 500 a $700 \mathrm{~cm}^{-1}$, e um menor teor dos mesmos na pirita beneficiada, comprovado pela queda na intensidade dos picos destas regiões.

As amostras apresentam pico em $3412 \mathrm{~cm}^{-1}$, atribuído a grupos com radical OH. A região próxima a $2963 \mathrm{~cm}^{-1}$ tem relação com ligações alifáticas; por volta de $1400 \mathrm{~cm}^{-1}$ têm-se bandas associadas a grupos carboxílicos. Comparando as piritas, com exceção do pico associado a grupos contendo radical $\mathrm{OH}$, os demais tiveram intensidade reduzida com o beneficiamento, provando que a acetona é eficiente na remoção da matéria orgânica. 
$\mathrm{O}$ pico em $1621 \mathrm{~cm}^{-1}$ (correspondente à fração caulinítica) foi reduzido, pois a separação densitária extraiu parte do material argiloso. A região de 533 e $470 \mathrm{~cm}^{-1}$ comprova que a pirita contém óxidos de ferro. Em $414 \mathrm{~cm}^{-1}$ tem-se o pico do dissulfeto de ferro.

Figura 2 - FTIR das piritas.

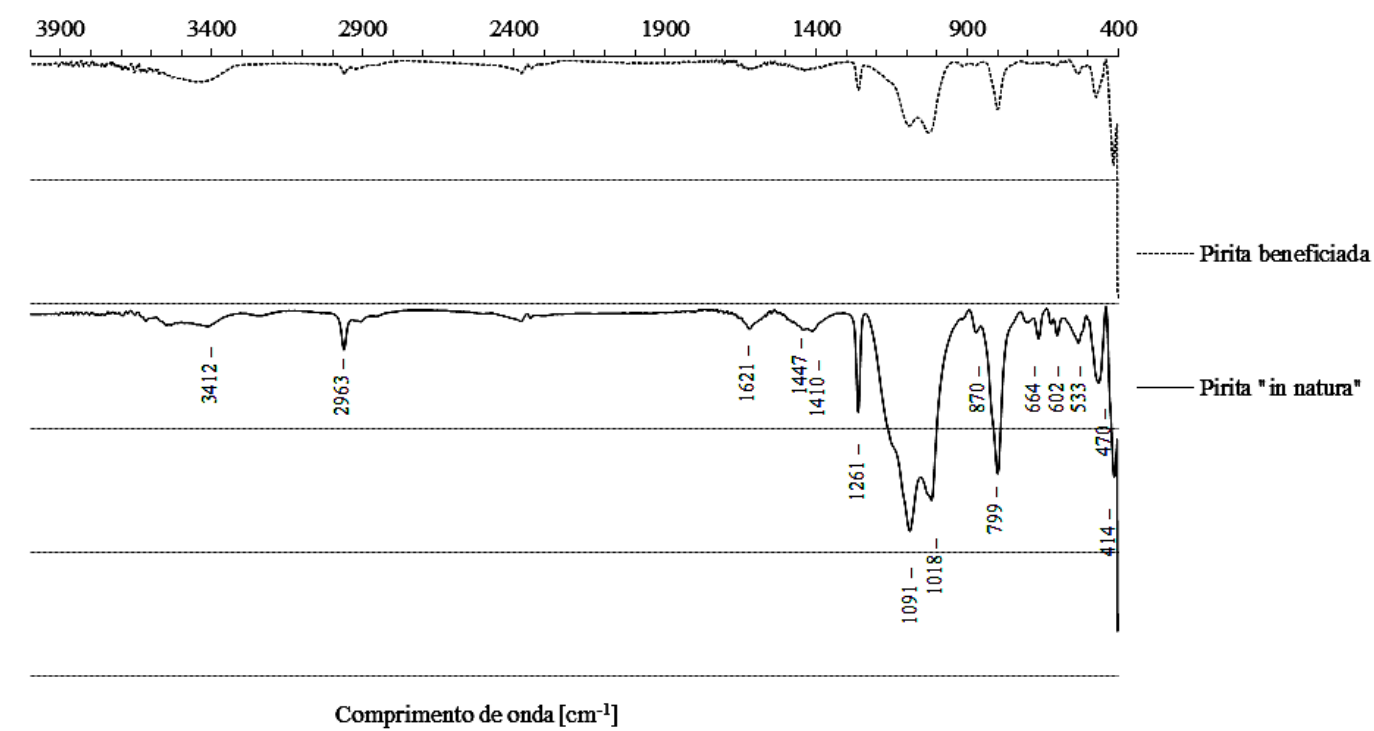

\section{CONCLUSÃO}

A pirita estudada é rica em matéria orgânica, óxidos e sulfatos de ferro. Embora os modelos estatísticos adotados na definição dos parâmetros de lixiviação não tenham se mostrado os mais adequados, os métodos de purificação propostos apresentaram resultados satisfatórios e contribuem para que a pirita deixe sua condição de resíduo sólido, podendo ser precursora de produtos de maior valor agregado.

\section{REFERÊNCIAS}

CHANDRA, A. P.; GERSON, A. R. The mechanisms of pyrite oxidation and leaching. Surface Science Reports, v. 65, p. 293-315, 2010.

NASCIMENTO, F. M. F.; MENDONÇA, R. M. G.; MACÊDO, M. I. F.; SOARES, P. S. M. Impactos ambientais nos recursos hídricos da exploração de carvão em Santa Catarina. Congresso Brasileiro de Mina a Céu Aberto \& II Congresso Brasileiro de Mina Subterrânea, 2002, Belo Horizonte, Anais.

OLIVEIRA, C. M.; OLIVEIRA, A.; ROSÁRIO, J. A.; DE NONI Jr., A.; PETERSON, M. Rota para Purificação de Pirita Proveniente da Mineração do Carvão. $21^{\circ}$ CBECIMAT Congresso Brasileiro de Engenharia e Ciência dos Materiais, 2014, Cuiabá, Anais.

PETERSON, Michael. Produção de sulfato ferroso a partir da pirita: desenvolvimento sustentável. 2008. 127 f. Tese (Doutorado em Engenharia Química). Universidade Federal de Santa Catarina, Florianópolis. 